\title{
SENTIMENT ANALYSIS OF CONTEMPORARY ANGLICAN SERMONS
}

\section{Dilai M. P.}

\section{INTRODUCTION}

This paper presents the research on emotions and religion. In particular, it aims at investigating Anglican preaching tradition through the prism of emotions which are discussed, expressed and evoked by contemporary sermons. According to Anna Wierzbicka ${ }^{1}$, language is a key issue in emotion research and the progress in understanding of emotions requires this issue be addressed. Exploring the language of sermons can yield much information not only about how emotions are described and expressed, but what a religion expects emotionally of its members ${ }^{2}$. Heightened expressivity of sermons may itself trigger some kind of emotional response, affecting listeners' attitudes and making persuasive appeals to actions ${ }^{3}$.

The contribution of this study lies in employing a corpus-based approach to sentiment analysis of Anglican sermons. Sentiment analysis, also known as opinion mining, is a challenging language processing and text mining problem, which deals with the computational study of opinions, sentiments and emotions expressed in text ${ }^{4}$. A corpus-based approach to sentiment analysis allows processing a large number of texts and automatically extract information on their positive/negative polarity, emotions, and evaluations expressed. Although sentiment-mining offers numerous research challenges (e.g. metaphorical expressions, sarcasm and lie detection, etc.), it promises insight into the study of preaching as intended emotional communication. Being a strategic ideological communication, preaching is aimed at constructing group identification mental models to produce and control beliefs and thereby motivate behaviours of the audience.

${ }^{1}$ Wierzbicka A. Emotions across languages and cultures: diversity and universals. Cambridge: Cambridge University Press, 1999. 362 p.

${ }^{2}$ Religion and emotion: Approaches and interpretations / J. Corrigan. New York : Oxford University Press, 2004. 359 p.

${ }^{3}$ Methods of exploring emotions / H. Flam et al. London: Routledge, 2015. 330 p.

${ }^{4}$ Liu B. Sentiment analysis and opinion mining. Morgan \& Claypool Publishers, 2012. 167 p. 
In the course of this study, I analyse 28 Anglican sermons by Justin Welby, the Archbishop of Canterbury ${ }^{5}$, delivered over the period of 20152017. Three experiments using different sentiment analysis programmes (LIWC $^{6}$, SentiStrength ${ }^{7}$ and Corpus Tool $3.3 \mathrm{~h}^{8}$ ) are carried out. The first one is a lexicon-based sentiment analysis. The second one deals with text segments (sentences) and, besides sentiment-marked words, takes into account some text features affecting the emotive load of the sentence. The third experiment lies in manual segment annotation of the texts of sermons taking into account the context and figurative language.

The algorithms to identify sentiment and sentiment strength can help understand the fundamental role of emotion in the religious discourse and also to identify affective utterances, potentially associated with people's opinions and behaviours.

\section{Previous research on emotions and religious discourse}

\subsection{A fundamental role of emotions in religion}

For centuries philosophers, theologians, psychologists and linguists have been discussing the essence and the role of emotions in religion. The overview presented by Robert Roberts in The Stanford Encyclopaedia of Philosophy concerning the different strands of overlapping research point out a fundamental role of emotions in religion'. Religious emotions are defined as ordinary human emotions elicited in religious contexts and made up of a feeling plus a specific sort of object ${ }^{10}$. Religious sentiment is viewed as a collective name for the many sentiments which religious objects may evoke, including religious fear, religious love, religious joy, etc. The peculiarity of this theory lies in the reference to a feeling, a bodily sensation, which is the element that makes the mental state into an emotion. According to the theologian Friedrich Schleiermacher (1768-1834), the essence of religion is piety and that piety consists in the feeling of absolute dependence, which corresponds

5 The Archbishop of Canterbury. Sermons. URL: https://www.archbishopofcanterbury.org/node/464/sermons/sermons/16 (дата звернення: 17.12.2020).

6 Linguistic Inquiry and Word Count. URL: http://liwc.wpengine.com (дата звернення: 17.12.2020).

${ }^{7}$ SentiStrength. URL: http://sentistrength.wlv.ac.uk (дата звернення: 17.12.2020).

${ }^{8}$ UAM Corpus tool. URL: http://www.corpustool.com (дата звернення: 17.12.2020).

9 Roberts R. Emotions in the Christian tradition. The Stanford Encyclopedia of Philosophy. 2016. URL: https://plato.stanford.edu/entries/emotion-Christian-tradition/ (дата звернення: 17.12.2020).

${ }^{10}$ James W. The varieties of religious experience. Doubleday : Garden City, New York, 1978. 516 p. 
to Receptivity and is the feeling of being acted upon by things in the world ${ }^{11}$. Sigmund Freud refers to "the source of the religious energy which is seized upon by the various Churches and religious systems" as an "oceanic" feeling, "a sensation of 'eternity', a feeling as of something limitless, unbounded" ". It is "a feeling of an indissoluble bond, of being one with the external world as a whole"13. According to the representative of the essentialist thinking Rudolf Otto, the feeling basic to religion is that of the awesome mystery, of the mysterious presence of the wholly other that inspires awe and devotion ${ }^{14}$. In an article titled "Why Christianity Works: An Emotion-Focused Phenomenological Account", Christian Smith ${ }^{15}$ proposes to explain the tenacity of Christianity in the face of various secularizing influences by reference to the character of religious emotions. Religious emotions are diverse and, as Jonathan Edwards ${ }^{16}$ claims, they embody religious teachings being important epistemic and ethical indicators of character, and in consequence there are conceptual criteria for their rightness that can and should be carefully clarified. Roberts ${ }^{17}$ concludes that religious emotions come in the usual types - contrition, gratitude, joy, fear, anxiety, anger, and so forth - and what makes them distinctive of one religion or another is their shaping by the teachings of the religion about God or the transcendent. Emotions are important to adherents of a religion because, like the actions that they sometimes motivate, they are expressions of the moral and spiritual life enjoined by the religion.

As a human activity, religion is "embedded in everyday life in the felt relations individuals experience with other persons, nature, and the holy personages to whom they are devoted"18. In fact, according to Paul Chilton ${ }^{19}$,

${ }^{11}$ Schleiermacher F. The Christian faith (2 volumes) / translated by H.R. MacKintosh and J.S. Stewart. New York : Harper and Row, 1963. 760.

${ }^{12}$ Freud S. Civilization and its discontents / translated by James Strachey. New York : W.W. Norton \& Company, 1961. 109 p.

${ }^{13}$ Freud S. Civilization and its discontents / translated by James Strachey. New York : W.W. Norton \& Company, 1961. 109 p.

${ }^{14}$ Otto R. Spiritual emotions. Grand Rapids : Wm. B. Eerdmans Publishing Company, 2007.

15 Smith Ch. Why Christianity works: An emotions-focused phenomenological account. Sociology of Religion 68 (2). 2007. P. 165-178.

${ }^{16}$ Edwards J. Religious affections / John E. Smith (ed.). New Haven : Yale University Press, 1959. $526 \mathrm{p}$.

${ }^{17}$ Roberts R. Emotions in the Christian tradition. The Stanford Encyclopedia of Philosophy. 2016. URL: https://plato.stanford.edu/entries/emotion-Christian-tradition/ (дата звернення: 17.12.2020).

${ }^{18}$ Corrigan J. The Oxford handbook on religion and emotion. New York : Oxford University Press, 2008. 522 p.

${ }^{19}$ Chilton P., Kopytowska M. Religion, language and the human mind. New York : Oxford University Press, 2017. 536 p. 
religion exists internally as emotions (as well as experiences and mental operations) in the mind-brain, and externally as bodily and linguistic practices, interacting internally in a complex relationship and externally with other brain-minds, often but not always in particular spatial and social settings. The use of language is manifestly part of those interactions.

\subsection{Language as a key issue in emotion research}

Speculating on the relationships between language and emotions, Michael Bamberg ${ }^{20}$ views language and emotion as two concurrent, parallel systems in use, and their relationship exists in that one system (emotions) impacts on the performance of the other (language). Both of them share their functionality in the communicative process between people. On the other hand, language in a way refers to, and therefore "reflects" objects in the world, among them the emotions.

According to Anna Wierzbicka ${ }^{21}$, language is a key issue in emotion research and the progress in understanding of emotions requires this issue be addressed. Emotions are a semantic domain, which governs the patterns of discourse. A semantic (cognitive) domain is to be investigated in a semantic metalanguage, i.e. in terms of indefinables or primitives (semantic universals) that are shared by all human languages ${ }^{22}$. Rom Harré ${ }^{23}$ takes emotions to be part of the domain of statements (actions and interactions). According to Harré's "emotionology", in order to identify and label correctly an emotion the following four sets of rules reflecting four different features of the feeling or display of an emotion need close attention: (1) a felt bodily disturbance, (2) a characteristic display, (3) the expression of a judgment, and (4) a particular illocutionary force. Following the anthropological, cultural model approaches, Harré adds the directive, cultural force of emotions to the representational system and discusses the structure of experience (shared knowledge). Harré views emotions as products of discourse constituted in interaction.

${ }^{20}$ Bamberg M. Language, concepts and emotions: the role of language in the construction of emotions. Language Sciences. 1997. № 19 (4). P. 309-340.

${ }^{21}$ Wierzbicka A. Emotions across languages and cultures: diversity and universals. Cambridge : Cambridge University Press, 1999. 362 p.

${ }^{22}$ Wierzbicka A. Emotion, language, and cultural scripts. Emotion and culture / S. Kitayama \& H.R. Markus (eds.). Washington, DC : American Psychological Association, 1994. P. 133-196.

${ }^{23}$ Harré R., Gillett G. The discursive mind. Thousand Oaks, CA : Sage Publications, 1994. DOI: http://dx.doi.org/10.4135/9781452243788 (дата звернення: 17.12.2020). 
Nancy Stein's ${ }^{24}$ approach to emotions combines aspects of both abovementioned. Emotions are schematically organized, they are part of a representational system, and these schemata are 'put to work' in responses to emotional events ${ }^{25}$. On the other hand, emotions are cognitions, constituting the motivational force for individuals to (re)act in a certain manner. Stein's goal-action-outcome theory accounts for cultural (and individual) variations by decomposing the general intentional states into distinct components which can be filled in and arranged in culturally variable ways. The acquisition of categorial distinctions between the basic as well as culturespecific emotions lies in its most basic form of knowledge of intentional action and of goal plans ${ }^{26}$.

Making use of the conceptual tools of cognitive linguistics, Zoltan Kövecses $^{27}$ showed that emotion concepts are characterized by metaphors, metonymies, and inherent concepts that converge on and create our cultural models of emotions. These models are mental representations of emotions. The cultural models of emotions present emotions as brief unfolding stories, which typically begin with some cause for the emotion and result in an action-like stage with several other stages in between these two. Thus, prototypical cultural models are idealised conceptualisations of an aspect of experience in a particular culture.

From cognitive linguists perspective both emotion and language are seen as complex mental systems consisting of different knowledge subsystems that interact in manifold ways ${ }^{28}$. Emotions are understood as the evaluative mental system within our cognitive apparatus. Based on the large range of linguistic features that serve to express emotion and evaluation, Monika Schwarz-Friesel shows that feelings and judgments can be conveyed explicitly, through lexical items and grammatical structures or implicitly, through ideational meanings. Implicitly conveyed evaluations have to be inferred by drawing specific emotive implicatures which depend on emotional representations based on culturally shaped encyclopaedic

${ }^{24}$ Stein N.L., Trabasso T. Liwag M.D. The Rashomon phenomenon: The role of framing and future-orientation in memories for emotional events. The Development of future oriented processes. Hillsdale, NJ : Lawrence Erlbaum Associates, 1994. P. 409-436.

${ }_{25}$ Bamberg M. Language, concepts and emotions: the role of language in the construction of emotions. Language Sciences. 1997. № 19 (4). P. 309-340.

${ }^{26}$ Stein N.L., Trabasso T. Liwag M.D. The Rashomon phenomenon: The role of framing and future-orientation in memories for emotional events. The Development of future oriented processes. Hillsdale, NJ : Lawrence Erlbaum Associates, 1994. P. 409-436.

${ }^{27}$ Kovecses Z. Emotion concepts. New York : Springer-Verlag, 1990. 230 p.

${ }^{28}$ Schwarz-Friesel M. Language and emotion. The cognitive linguistic perspective Emotion in Language: Theory - research - application. Consciousness \& Emotion Book Series. 2015. № 10. P. 157-174. 
knowledge. In those cases, the utterance is aimed to give an affective judgment about the referent or state-of-affairs in question and reveals the attitude of the speaker.

\section{Sentiment analysis methodologies}

Sentiment analysis, often referred to as opinion mining, is the field of study that investigates people's opinions, sentiments, evaluations, appraisals, attitudes, and emotions towards entities such as products, services, organizations, individuals, issues, events, topics, and their attributes ${ }^{29}$. Sentiment analysis mainly focuses on opinions which express or imply positive or negative sentiments. Since early 2000 , sentiment analysis has grown to be one of the most active research areas in natural language processing, data mining, Web mining, and text mining.

Due to a wide set of applications, especially in business and social domain, a number of sentiment analysis tools are available. Some of them have a lexicon of positive and negative words, such as General Inquirer ${ }^{30}$, WordNet Affect ${ }^{31}$, SentiWordNet ${ }^{32}$ or QWordNet ${ }^{33}$, and mainly count their frequency. The modifications of this approach include the detection of words that intensify sentiment in other words (e.g., really love, absolutely hate) and overall sentence structures ${ }^{34}$. Another approach is based on identifying text features that could potentially be subjective in certain contexts and then use contextual information to determine whether they are subjective in each new context $^{35}$. A primarily linguistic approach to opinion mining makes use of

${ }^{29}$ Liu B. Sentiment analysis and opinion mining. Morgan \& Claypool Publishers, 2012. 167 p.

${ }^{30}$ Stone Philip J., Dunphy Dexter C., Smith Marshal S., Ogilvie D.M. The general inquirer: A computer approach to content analysis. Cambridge, MA : The MIT Press, 1966. $651 \mathrm{p}$.

${ }^{31}$ Strapparava C., Valitutti A. Wordn et-affect: an affective extension of wordnet. Proceedings of the 4th International Conference on Language Resources and Evaluation. Lisbon, 2004. P. 1083-1086.

${ }^{32}$ Baccianella S., Esuli A., Sebastiani F. SentiWordNet 3.0: An enhanced lexical resource for sentiment analysis and opinion mining. Proceedings of the Seventh conference on International Language Resources and Evaluation. Valletta, Malta, 2010. P. 2200-2204.

33 Agerri R., García-Serrano A. Q-WordNet: Extracting polarity from WordNet senses. Proceedings of the Seventh conference on International Language Resources and Evaluation. Valletta, Malta, 2010. P. 2301-2305.

34 Turney P.D. Thumbs up or thumbs down? Semantic orientation applied to unsupervised classification of reviews. Proceedings of the 40th annual meeting of the Association for Computational Linguistics (ACL) (July 6-12, 2002). Philadelphia, PA. 2002. P. 417-424.

${ }^{35}$ Wiebe J., Wilson T., Bruce R., Bell M., Martin M. Learning subjective language. Computational Linguistics. 2004. № 30 (3). P. 277-308. 
simple rules based upon compositional semantics (information about likely meanings of a word based upon the surrounding text) to detect the polarity of an expression ${ }^{36}$.

In course of this research, in order to reveal emotional loading of contemporary Anglican sermons, we are to carry out and compare the outcomes of three sentiment analysis experiments. The first one is a lexiconbased sentiment analysis of the texts of sermons. The second one deals with text segments (sentences) and, besides sentiment-marked words, takes into account some text features, which affect the emotive load of the sentence. The third experiment lies in manual segment annotation of the texts of sermons.

Experiment 1. The aim of the first experiment is to extract attitudinal assessment conveyed by individual lexical items in the analysed corpus of sermons. This can be archived by using LIWC: Linguistic Inquiry and Word Count programme, a lexicon-based resource designed to mine the semantic and affective information associated with lexical items. LIWC has been created by psychology researchers to investigate the connection between language and psychology ${ }^{37}$.

The programme was designed to analyse over 70 dimensions of language, including 4 general descriptor categories (total word count, words per sentence, percentage of words captured by the dictionary, and percentage of words longer than six letters); 22 standard linguistic dimensions (e.g., percentage of words in the text that are pronouns, articles, auxiliary verbs, etc.); 32 word categories tapping psychological constructs (e.g., affect, cognition, biological processes); 7 personal concern categories (e.g., work, home, leisure activities), 3 paralinguistic dimensions (assents, fillers, nonfluencies) and 12 punctuation categories (periods, commas, etc.). The tool includes the main text analysis module along with a group of built-in dictionaries. The text analysis module was created in the Java programming language. LIWC analyses .txt and $\operatorname{doc}(\mathrm{x})$ files. The output is given in .txt form but can be easily transferred to an excel file.

The LIWC2015 master dictionary is composed of almost 6,400 words, word stems, and selected emoticons. For each dictionary word, there is a corresponding dictionary entry that defines one or more word categories. For example, the word cried is part of five word categories: Sadness, Negative Emotion, Overall Affect, Verb, and Past Focus. Hence, if the word cried was found in the target text, each of these five subdictionary scale scores would

${ }^{36}$ Choi Y., Claire C. Learning with compositional semantics as structural inference for subsentential sentiment analysis. Proceedings of the Conference on Empirical Methods in Natural Language Processing. 2008. P. 793-801.

${ }^{37}$ Pennebaker J. W., Mehl M.R., Niederhoffer K. Psychological aspects of natural language use: Our words, our selves. Annual Review of Psychology. 2003. № 54. P. 547-577. 
be incremented. Many of the LIWC2015 categories are arranged hierarchically. All sadness words, by definition, will be categorized as negative emotion and overall affect words.

In contrast to the machine learning approaches, a list of emotion-bearing words, used to detect positive and negative emotion in text, has been compiled and validated using panels of human judges and statistical testing.

In this study, the focus is on such categories as affect, positive emotions and negative emotions, including anxiety, anger and sadness (see Table 1).

Table 1

LIWC2015 output

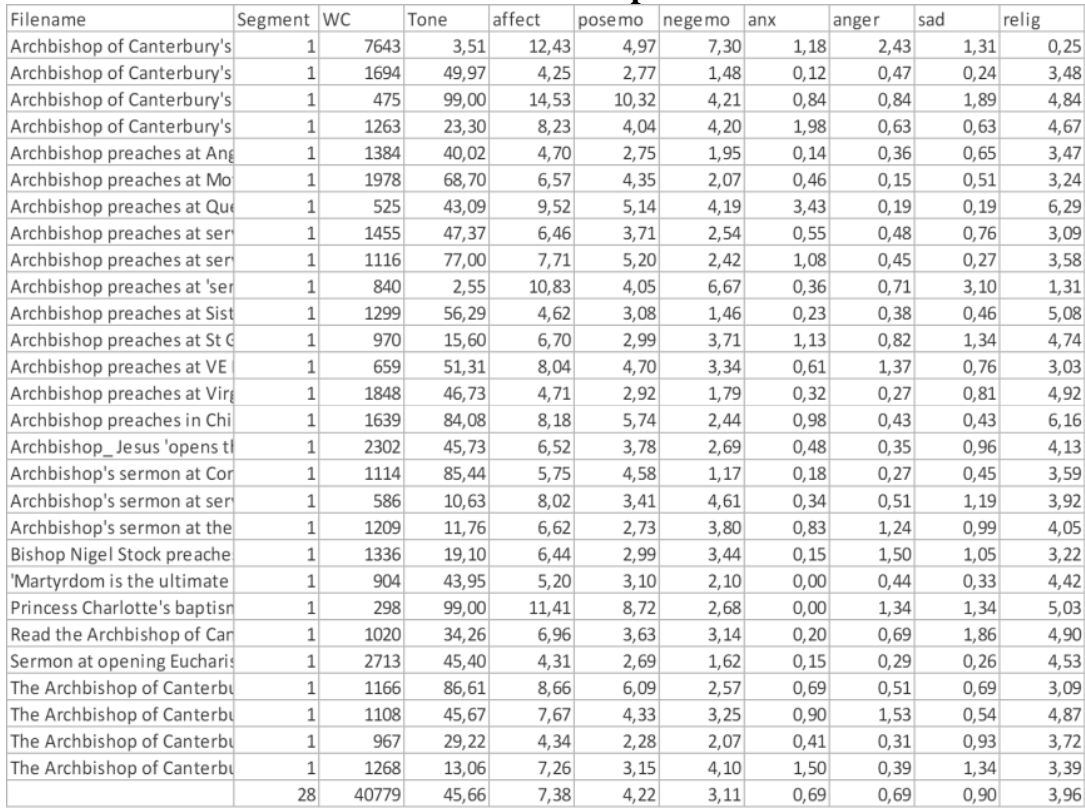

LIWC calculates the prevalence of emotion in text, rather than attempting to diagnose a text's overall emotion or emotion strength.

Experiment 2. The SentiStrength ${ }^{38}$ algorithm attempts to identify the polarity of sentiment in text and also detects the strength of sentiment expressed $^{39}$. SentiStrength reports two sentiment strengths: -1 (not negative)

${ }^{38}$ SentiStrength. URL: http://sentistrength.wlv.ac.uk (дата звернення: 17.12.2020).

${ }^{39}$ Thelwall M., Buckley K., Paltoglou G., Cai D., Kappas A. Sentiment strength detection in short informal text. Journal of the American Society for Information Science and Technology. 2010. № 61 (12). P. 2544-2558. 
to -5 (extremely negative), 1 (not positive) to 5 (extremely positive), based on the research from psychology, which has revealed that we process positive and negative sentiment in parallel (mixed emotions). The programme can also report binary (positive/negative), trinary (positive/negative/neutral) and single scale $(-4$ to +4$)$ results.

The SentiStrength algorithm is based on the information given in various files, including:

- the EmotionLookUpTable is a list of emotion-bearing words, each one with the word then a tab, then an integer 1 to 5 or -1 to -5 . Strengths of +1 and -1 have no effect on the program.

- negatingWordList.txt reverses the polarity of subsequent words, e.g. not happy is negative.

- BoosterWordList.txt increases sentiment intensity, e.g. very happy is more positive than happy.

- IdiomLookupTable.txt overrides the sentiment strength of the individual words in the phrase.

The above factors are applied separately to each sentence. Sentiment Strength analysis output is a copy of the text file with overall comment assigned with the most positive of its sentence emotions and the most negative of its sentence emotions. Table 2 shows how the results transformed into Excel look like.

Despite quite consistent sentence sentiment detection, the obtained findings appear rather robust due to the following factors:

1) A positive or negative sentiment word may have opposite orientations in different contexts and domains. For instance, the words in bold in the sentences are negatively-marked but in the given contexts their value changes.

If people could be manipulated and tricked into being good Christians or bribed into being good Christians, He would have sent some kind of crooked person who was good at trickery.

The common good, truly interpreted in the light of the scripture, its horizons opened up by the radicality of the gospel, demands from us our own radicality that can only come from the overflowing of the Spirit of God within us.

2) Metaphorical expressions.

Hope flowers in the desert of suffering when it is watered by communities of love, for through them Christ comes, light dawns, and lives shattered in grief and pain find astonishingly that they will live again.

In the darkness of fear, every threat is magnified out of all reality, and it is only resolved with light. 


\section{SentiStrength output}

\begin{tabular}{|c|c|c|c|}
\hline Positive & Negative & Sum & Sentiment score \\
\hline 2 & -1 & 1 & $\begin{array}{l}\text { When[0] our[0] lives }[0] \text { are }[0] \text { surrendered }[0] \\
\text { it[0] is[0] God[0] who[0] can[0] be[0] trusted[1] } \\
\text { to[0] take[0] that }[0] \text { offering[0] and }[0] \text { bring[0] } \\
\text { it }[0] \text { to[0] the[0] glory[1] of }[0] \text { His }[0] \text { name[0] } \\
\text { and[0] in[0] so[0] doing[0] to[0] offer[0] life[0] } \\
\text { to[0] all[0] the[0] world[0] [[Sentence }=-1,2=\text { word } \\
\text { max, } 1-5]][[[2,-1 \text { max of sentences]]] }\end{array}$ \\
\hline 1 & -2 & -1 & $\begin{array}{l}\text { In[0] Luwum[0] offering[0] and[0] dying[-1] as[0] } \\
\text { with[0] the[0] other[0] martyrs[-1] the[0] name[0] } \\
\text { of[0] Christ[0] is[0] held[0] high[0] [[Sentence=- } \\
2,1=\text { word max, } 1-5]][[[1,-2 \text { max of sentences }]]]\end{array}$ \\
\hline 1 & -3 & -2 & $\begin{array}{l}\text { We[0] recalled[0] that }[0] \text { fact }[0] \text { in[0] our }[0] \\
\text { silence[0] on[0] the }[0] \text { anniversary[0] of }[0] \text { the }[0] \\
\text { deaths[-2] of }[0] \text { the }[0] \text { Coptic[0] martyrs[-1] } \\
{[[\text { Sentence=-3,1=word max, } 1-5]][[[1,-3 \text { max of }} \\
\text { sentences]]] }\end{array}$ \\
\hline 1 & -4 & -3 & $\begin{array}{l}\text { In[0] that }[0] \text { terrible}[-3] \text { and }[0] \text { evil[-2] event[0] } \\
\text { just [0] over[0] a[0] year[0] ago[0] God[0] used[0] } \\
\text { the[0] force[-1] of }[0] \text { evil[-2] to[0] defeat[0] evil[- } \\
\text { 2] [[Sentence=-4,1=word max, } 1-5]][[[1,-4 \text { max of } \\
\text { sentences]]] }\end{array}$ \\
\hline 2 & -3 & -1 & 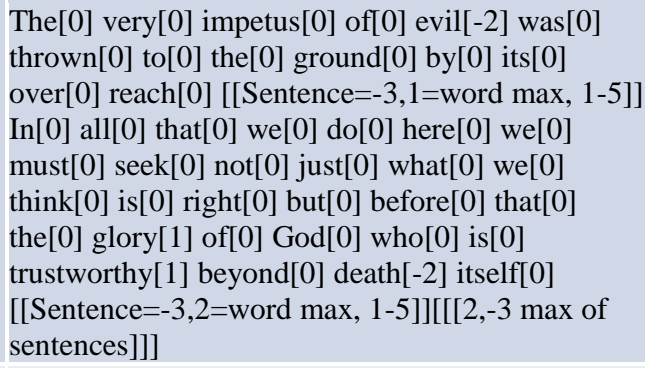 \\
\hline 2 & -1 & 1 & $\begin{array}{l}\text { When[0] our[0] lives }[0] \text { are }[0] \text { surrendered }[0] \\
\text { it[0] is[0] God[0] who[0] can[0] be[0] trusted }[1] \\
\text { to[0] take[0] that }[0] \text { offering }[0] \text { and }[0] \text { bring }[0] \\
\text { it }[0] \text { to[0] the }[0] \text { glory[1] of }[0] \text { His }[0] \text { name }[0] \\
\text { and[0] in[0] so[0] doing[0] to[0] offer }[0] \text { life }[0] \\
\text { to[0] all[0] the[0] world[0] [[Sentence }=-1,2=\text { word } \\
\text { max, } 1-5]][[[2,-1 \text { max of sentences]]] }\end{array}$ \\
\hline
\end{tabular}


3) Sentiment shifters. These are expressions that are used to change the sentiment orientations, e.g., from positive to negative or vice versa:

a. Negation words like not, never, none, nobody, nowhere, neither, and cannot are the most common type of sentiment shifters $(3,4,5)$.

(1) Yet it should not be a path of solitary suffering, because the church is a family of witnesses to the reality of Jesus.

(2) None of us like being defined by others, [...].

(3) [...] the Spirit of God who will make possible the impossible revolutio $n$, the impossible revolution to be achieved without violence, to be achieved without hatred, to be achieved in blessing and loving and serving and transf orming the society in which we live.

b. Modal auxiliary verbs (e.g., would, should, could, might, must) as a rule change sentiment orientation $(6,7)$.

(4) We could just be overwhelmed with sadness, or despair - but those we remember today call us to something far better, [...].

(5) Until recent years, central and western Europe could feel confident that reconciliation was well established and that never again would any of us either go ourselves or send our children or grandchildren to fight other Europeans in the field of battle.

The research proceeds with building a manually annotated dataset which allows taking into account the context determining emotional loading of words and utterances.

Experiment 3. The UAM Corpus tool 3.0. ${ }^{40}$ enables segmented manual annotation using built-in Appraisal framework ${ }^{41}$. Fundamentally, Appraisal framework was designed to explore, describe and explain evaluative uses of language, including the ways the language is used to adopt stances, to construct textual personas and to manage interpersonal positioning and relationships. A central contribution of appraisal theory is the Attitude system (see Figure 1) encompassing three basic types of attitudes that are divided into several subtypes.

40 UAM Corpus tool. URL: http://www.corpustool.com (дата звернення: 17.12.2020).

${ }^{41}$ Martin J. R., White P.R.R.. The language of evaluation, appraisal in English. London \& New York : Palgrave Macmillan, 2005. 277 p. 


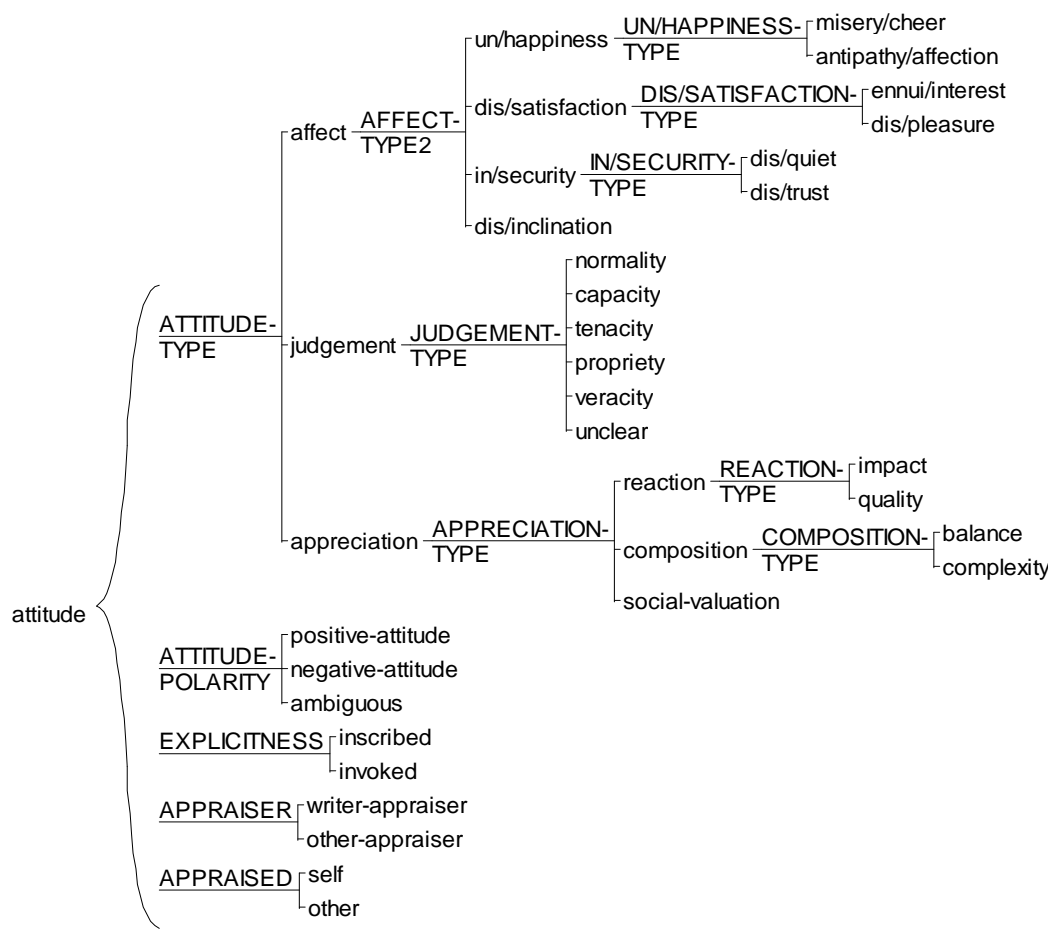

Fig. 1. Attitude system (Martin \& White 2005)

The basic types are affect, judgment, and appreciation. Affect expresses a person's internal emotional state. Judgment evaluates a person's social behaviour in a context. Appreciation evaluates norms about how things, performances, and naturally occurring phenomena are valued, when this evaluation is expressed as being a property of the object. The attitude can be of positive or negative polarity. In addition, there are two ways that attitude segments can be expressed: implicitly or explicitly. Linguistically, these are referred to as inscribed and evoked appraisal. Evoked appraisal includes such phenomena as sarcasm, figurative language, and metaphoric uses of language.

Figure 2 shows manual annotation using Attitude system. For example, the annotation of the expression the huge privilege reads: attitude, appreciation, reaction, quality, positive attitude, inscribed, writer-appraiser, self-appraised. 


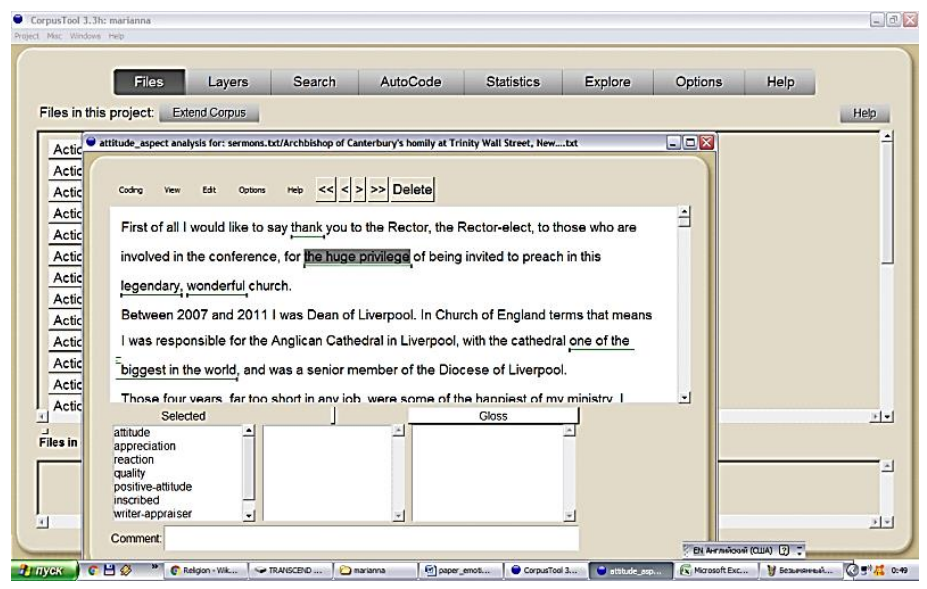

Fig. 2. Manual annotation using built-in Attitude System

Example (8) shows attitude type segment marking.

(6) And all these martyrs in their testimony to the resurrection point at us and ask, "in your comfort [affect], in your great [appreciation] buildings..., in your well organised [appreciation] societies, you who have lived these many decades under governments that welcome [judgement] opposition, and that are led by those who seek honourably [judgement] and honestly [judgement] to serve the people, are you still witnesses?"

Each segment expresses a single (positive or negative) opinion. In most cases, we need to take into account additional details, given in linguistic and extralinguistic contexts. As a rule, strong positive verbs determine the polarity of the segment when they are combined with positive nouns (9).

(7) Because of the resurrection of Jesus from the dead the cruel are overcome, evil is defeated, martyrs conquer.

It should be noted that classifying opinion texts at the discourse level or the sentence level is often insufficient for applications because they do not identify opinion targets or assign sentiments to such targets. Complex sentences often have different sentiments on different targets (10).

(8) The very solidity of our institutions, the beauty of our buildings, the historic richness of our liturgy and music all conspire together to say to us that we have achieved much, and the future is in our hands: when we then look at the context in which we live, the changes in our society, the contradictions and struggles within our own beliefs and understandings of the call and purpose of God, to have all in our own hands often feels insecure and leads us to fear. 
That is, the sentence is positive about the achievements, including institutions, buildings, our liturgy, the future, but negative about the context in which we live, the changes in our society, our own beliefs and understanding of the call and purpose of God, having all in our hands. In this latter sentence, even the clause level classification is insufficient. There is a need for an aspect-based sentiment analysis (also called the feature-based opinion mining) focused on the opinion target or the aspect level.

\section{Results and discussion}

The analysis carried out at the lexical level using LIWC2015 programme reveals that on average $7.38 \%$ of the total number of words in Anglican sermons express affect. The words with positive connotations make up about $4.22 \%$ of words count and outnumber the words which express negative emotions $(3.11 \%)$ (see figure 3 ).

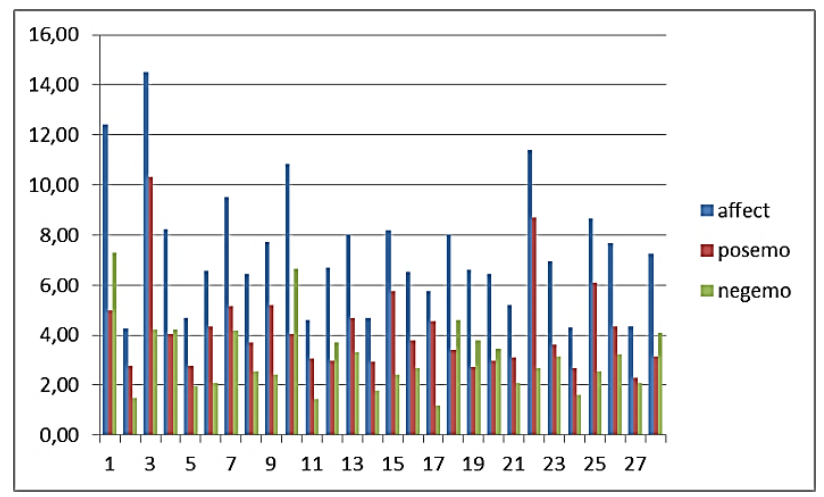

Fig. 3. LIWC2015 results: affect

As for the negative lexicon of sermons, the words expressing the emotion of sadness (0.90) are more common than the ones marked as anxiety and anger (see figure 4), they include: abandoned, abandons, agony, alone, bereaved, bereavement, broke, cried, cries, cry, crying, despair, despairing, despairs, devastate, devastated, devastating, disappointed, disappointment, discouragement, doomed, emptiness, empty, failed, failings, fails, failure, failures, grief, grieve, grim, grimly, helpless, hopeless, hurt, hurting, isolated, isolation, lonely, longing, longings, lose, losers, losing, loss, losses, lost, low, lowered, miserable, miss, missed, missing, mourn, mourners, neglect, overwhelmed, reject, rejected, rejection, sad, sadness, sorrow, sorrows, suffer, suffered, suffering, suffers, tears, tragedies, tragedy, tragic, tragically, unhappy, unimportant, useless, weep, weeps, wept. 


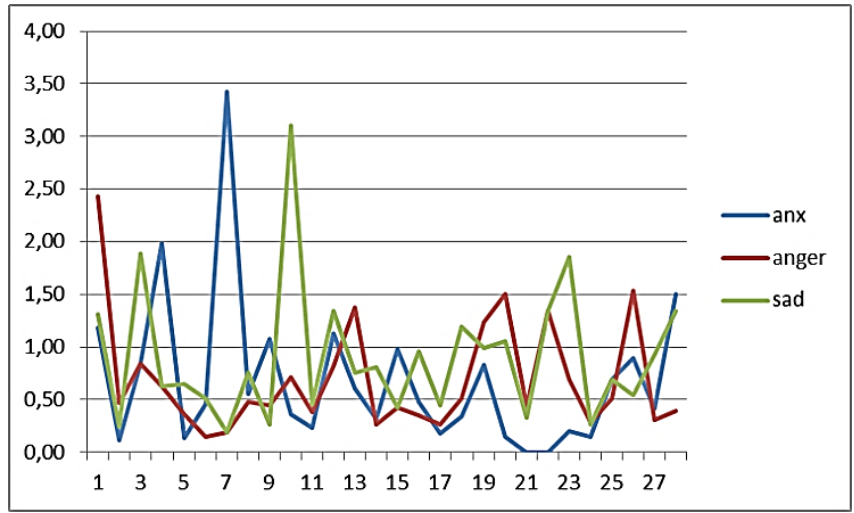

Fig. 4. LIWC2015 results: negative lexicon

In addition, the programme enables the extraction of the religious lexicon (117 items) which is marked mostly neutral (except for 17 positive and 4 negative words (see table 3 )).

Table 3

LIWC2015 results: religious lexicon

\begin{tabular}{|c|c|c|c|c|c|c|}
\hline Word & affect & posemo & negemo & anx & anger & sad \\
\hline worshipped & $\mathrm{X}$ & $\mathrm{X}$ & & & & \\
\hline worship & $\mathrm{X}$ & $\mathrm{X}$ & & & & \\
\hline sins & $\mathrm{X}$ & & $\mathrm{X}$ & & & \\
\hline sin & $\mathrm{X}$ & & $\mathrm{X}$ & & & \\
\hline immorality & $\mathrm{X}$ & & $\mathrm{X}$ & & & \\
\hline heavenly & $\mathrm{X}$ & $\mathrm{X}$ & & & & \\
\hline heaven & $\mathrm{X}$ & $\mathrm{X}$ & & & & \\
\hline faiths & $\mathrm{X}$ & $\mathrm{X}$ & & & & \\
\hline faithfulness & $\mathrm{X}$ & $\mathrm{X}$ & & & & \\
\hline faithfully & $\mathrm{X}$ & $\mathrm{X}$ & & & & \\
\hline faithful & $\mathrm{X}$ & $\mathrm{X}$ & & & & \\
\hline faith & $\mathrm{X}$ & $\mathrm{X}$ & & & & \\
\hline doomed & $\mathrm{X}$ & & $\mathrm{X}$ & & & $\mathrm{X}$ \\
\hline divine & $\mathrm{X}$ & $\mathrm{X}$ & & & & \\
\hline blessing & $\mathrm{X}$ & $\mathrm{X}$ & & & & \\
\hline blessed & $\mathrm{X}$ & $\mathrm{X}$ & & & & \\
\hline bless & $\mathrm{X}$ & $\mathrm{X}$ & & & & \\
\hline
\end{tabular}


As for the relation between the emotive lexicon use and text composition, it has been revealed that as a rule the most emotionally loaded is the ending of the sermons (see figure 5).

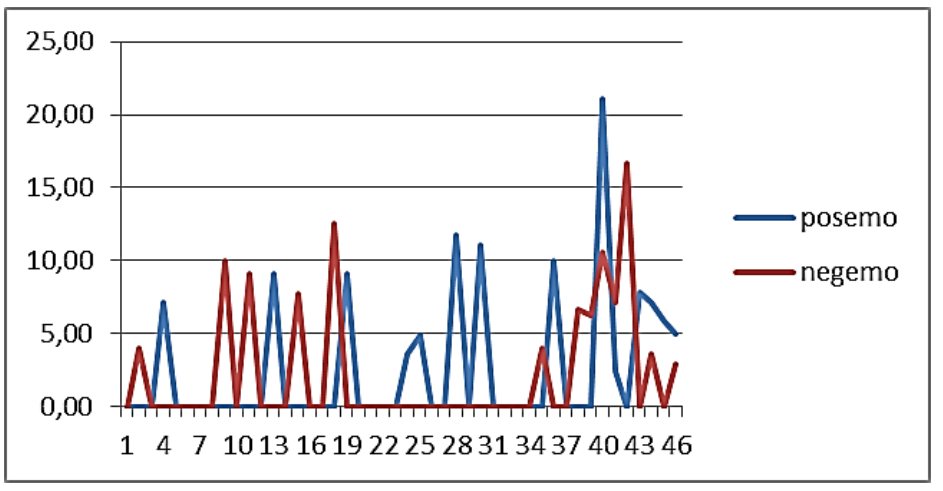

Fig. 5. LIWC2015 results: emotive lexicon use and text composition

The SentiStrength findings prove that contemporary texts of sermons are emotionally loaded (53\% of segments are either positive or negative) (see table 4, figure 6). It has been revealed that at the sentence level the average sentiment strength of the sermon corpus is negative $(-0.14)$. The obtained corpus strength scale shows that negative sentiments $(-4$ to -1$)$ prevail positive ones (1 to 4 ), they make up $28.7 \%$, and include very strong negative loaded segments $(-4-0.4 \%)$.

About $7.2 \%$ of sentences are marked -3 and -4 and feature combinations of extremely strong negative words, which leads to the intensification of negative sentiment of the segment, for instance: appalling [-3], violence [-3], terrible [-3], suffering [-3], cruel [-3], murder [-3], devastating [-4], destruction [-1], pain [-3], and [0], despair [-3], grief [-3].

Here are some examples of the most common words corresponding to the sentiment strength markings: [-4] destructing and destruction; [-3] violence, cruel, cruelty, cry, fear, murdered, suffer, terrible, sad, hate, hatred, despair, killed, appalling, etc. [-2] death, dead, evil, war, shock, persecution, brutality, mourners, failed, etc. [-1] disagreement, martyrs, poorest, poverty, weak, exile, enemy, retirement, burn, etc. [1] kind, faith, faithful, blessing, like, values, privilege, etc. [2] hope, great, love, passionate, goodness, beautiful, happiest, affection, etc. [3] loving, loved, excellent etc. 
Table 4

SentiStrength analysis output

\begin{tabular}{|c|c|c|c|}
\hline & & Frequency & Percentage $\%$ \\
\hline \multirow{9}{*}{ Scale } & -4 & 11 & .4 \\
\hline & -3 & 172 & 6.8 \\
\hline & -2 & 173 & 6.8 \\
\hline & -1 & 373 & 14.7 \\
\hline & 0 & 1197 & 47.0 \\
\hline & 1 & 353 & 13.9 \\
\hline & 2 & 239 & 9.4 \\
\hline & 3 & 27 & 1.1 \\
\hline & Total & 2545 & 100.0 \\
\hline
\end{tabular}

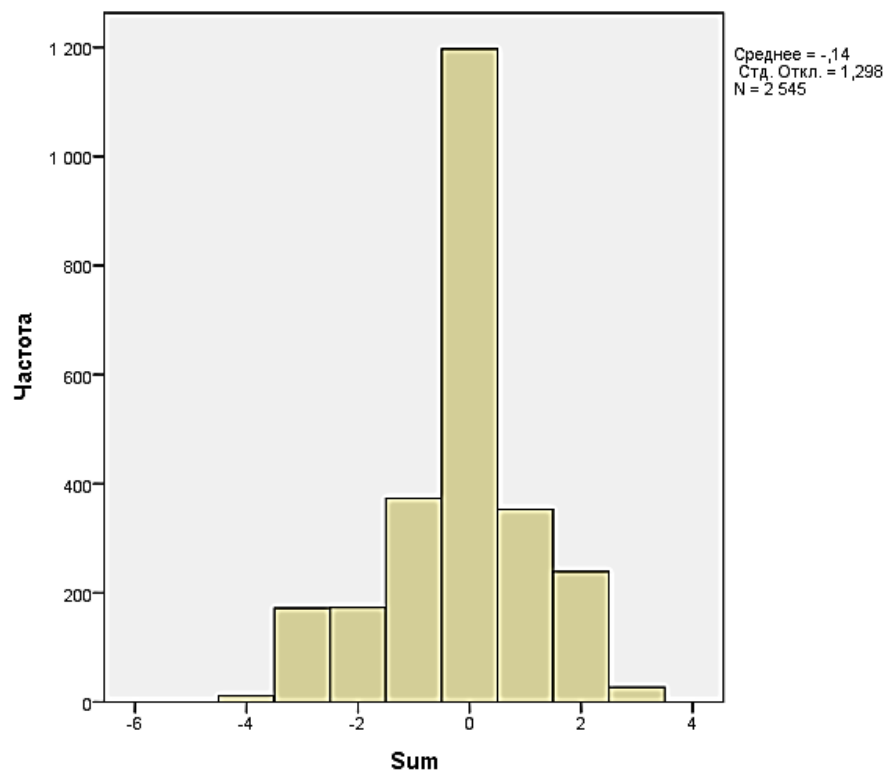

Fig. 6. SentiStrength analysis output

The manual annotation made using UAM Corpus Tool 3.3h shows that Anglican sermons most frequently express appreciation and have positive polarity (see figures 7,8 ). 


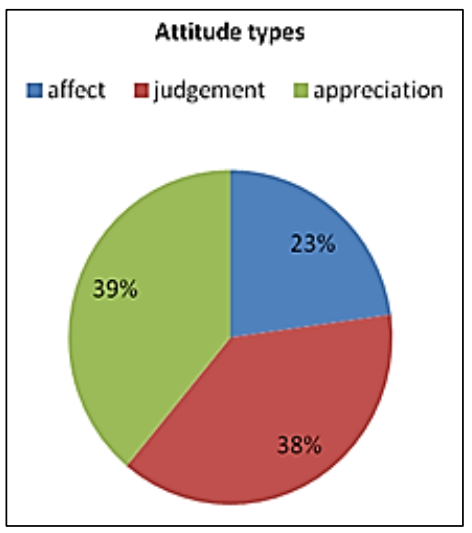

Fig. 7. UAM CorpusTool33h results: attitude types

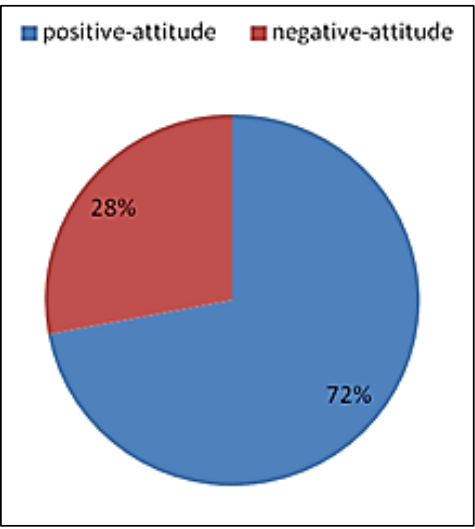

Fig. 8. UAM CorpusTool33h results: polarity

In most cases attitudes are expressed explicitly (71.14\%). It has been revealed that invoked judgement the polarity of which is determined by the context is much more common than affect and appreciation (48.84\%). Example (11) shows that the sentiments of the words martyrdom and martyrs could be understood only by analysing the context.

(9) Martyrdom has gained a bad name - associated with violence, linked to cruelty, involving manipulation and random death. But when we consider Christian martyrs like Luwum, we see something else. Instead of violence, there is peace and a seeking of reconciliation. Instead of cruelty there is dignity and mercy.

In example (12) the segment in bold does not express a negative judgement despite the fact that it contains negatively marked words.

(10) Christians must resist without violence the persecution they suffer and support persecute communities, with love and goodness and generosity.

The metaphorical expressions in examples $(13,14)$ imply positive affect.

(11) The stone has moved and the light of life floods into our lives, our churches, the joy of Christ is among us and in us, the certainty of life forever is offered to all who say 'yes': because Jesus is risen.

(12) The disciples returned to Jerusalem immediately, still not knowing all the answers, but with just the beginnings of hope and a sense that there is a future, in which life conquers death, in which justice confronts evil and overcomes it, in which pain and trauma and memory are healed and do not dominate our lives. 
The appraiser is mostly the preacher $(79.53 \%)$, less frequently others (Bible, authority, etc.). It is common that others are appraised in the sermons, the inclusive self often refers to the congregation, expressed by the pronoun we.

In most cases appreciation takes a form of reaction (see figure 9), predominantly of an explicit positive quality type.

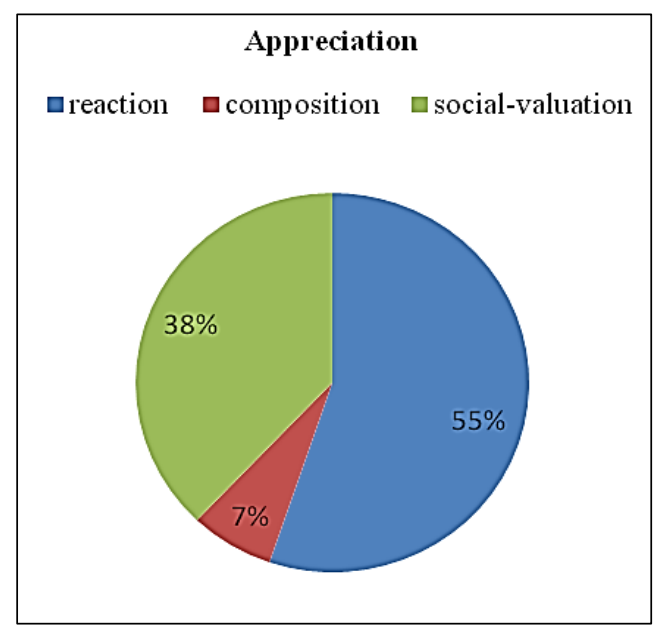

Fig. 9. UAM CorpusTool33h results: appreciation

\section{CONCLUSIONS}

The outcomes of the experiments carried out using different NLP tools confirmed the emotional loading of contemporary Anglican sermons. Although the programmes which we applied (LIWC, SentiStrength, UAM Corpus Tool), feature specific built-in data and focus on different levels of language analysis, they complement each other. The findings showed that the positive lexicon prevails over the negative one. However, we revealed much stronger negative sentiment at the segment/sentence level, in particular due to the common combinations of extremely strong negative words. Manual segment annotation enabled taking into account the context, homonymy and figurative language, including metaphorical expressions, which abound in the texts of sermons. As a result, a conclusion can be drawn that positive attitudes expressing appreciative reaction prevail in the analysed sermons.

Further research on comparing the emotional loading of Christian sermons (Catholic, Protestant, Orthodox etc.) appears to be promising from the perspective of aspect-based sentiment analysis. Processing large volumes 
of text and extracting opinion targets and sentiments on the targets, may provide insights into the role of emotions in preaching as a strategic ideological communication.

\section{SUMMARY}

The paper presents a corpus-based approach to the sentiment analysis of contemporary Anglican sermons. This methodology allows processing large volumes of text and extract opinions which express or imply positive or negative sentiments (Liu 2012). To mine the opinion based on sentiment lexicon I make use of LIWC (Linguistic Inquiry and Word Count) and SentiStrength programmes. In addition, taking into account the fact that emotional loading of words is context dependent, attitudinal meanings have been extracted within utterances by building a manually annotated dataset using the UAM Corpus tool 3.3h. The application makes it possible to explore both how attitudes are explicitly presented in the texts of sermons and how they may be implied, presupposed or assumed. The UAM Corpus tool ships with a predefined coding scheme based on the Appraisal framework, designed to describe and explain evaluative uses of language (Martin \& White 2005). The texts of sermons are annotated in code-segments manner, assigning the features of the attitude type (affect, judgment, appreciation), the attitude polarity (positive vs. negative sentiment), explicitness (inscribed vs. invoked), appraiser (preacher or other) and appraised (sermon specific collective self vs. other). The application of NLP tools allows obtaining unbiased findings that shed light on how preachers pass judgements on people and their behaviour, happenings and states of affairs causing emotional reaction and thereby maintain group identity.

\section{REFERENCES}

1. Agerri R., García-Serrano A. Q-WordNet: Extracting polarity from WordNet senses. Proceedings of the Seventh conference on International Language Resources and Evaluation. Valletta, Malta, 2010. P. 2301-2305.

2. Baccianella S., Esuli A., Sebastiani F. SentiWordNet 3.0: An enhanced lexical resource for sentiment analysis and opinion mining. Proceedings of the Seventh conference on International Language Resources and Evaluation. Valletta, Malta, 2010. P. 2200-2204.

3. Bamberg M. Language, concepts and emotions: the role of language in the construction of emotions. Language Sciences. 1997. № 19 (4). P. 309-340.

4. Chilton P., Kopytowska M. Religion, language and the human mind. New York : Oxford University Press, 2017. 536 p.

5. Choi Y., Claire C. Learning with compositional semantics as structural inference for subsentential sentiment analysis. Proceedings of the 
Conference on Empirical Methods in Natural Language Processing. 2008. P. 793-801.

6. Edwards J. Religious affections / John E. Smith (ed.). New Haven : Yale University Press, 1959. 526 p.

7. Freud S. Civilization and its discontents / translated by James Strachey. New York : W.W. Norton \& Company, 1961. 109 p.

8. Harré R., Gillett G. The discursive mind. Thousand Oaks, CA: Sage Publications, 1994. URL: http://dx.doi.org/10.4135/9781452243788 (дата звернення: 17.12.2020).

9. James W. The varieties of religious experience. Doubleday : Garden City, New York, 1978. 516 p.

10. Kovecses Z. Emotion concepts. New York : Springer-Verlag, 1990. 230 p.

11. Linguistic Inquiry and Word Count. URL: http://liwc.wpengine.com (дата звернення: 17.12.2020)

12. Liu B. Sentiment analysis and opinion mining. Morgan \& Claypool Publishers, 2012. $167 \mathrm{p}$.

13. Martin J. R., White P.R.R. The language of evaluation, appraisal in English. London \& New York : Palgrave Macmillan, 2005. 277 p.

14. Methods of exploring emotions / H. Flam et al. London : Routledge, $2015.330 \mathrm{p}$.

15. Otto R. Spiritual emotions. Grand Rapids : Wm. B. Eerdmans Publishing Company, 2007.

16. Pennebaker J.W., Mehl M.R., Niederhoffer K. Psychological aspects of natural language use: Our words, our selves. Annual Review of Psychology. 2003. № 54. P. 547-577.

17. Corrigan J. Religion and emotion: Approaches and interpretations. New York : Oxford University Press, 2004. 359 p.

18. Roberts R. Emotions in the Christian tradition. The Stanford Encyclopedia of Philosophy. 2016. URL: https://plato.stanford.edu/entries/ emotion-Christian-tradition/ (дата звернення: 17.12.2020).

19. Schleiermacher F. The Christian faith ( 2 volumes) / translated by H.R. MacKintosh and J.S. Stewart. New York : Harper and Row, 1963. 760.

20. Schwarz-Friesel M. Language and emotion. The cognitive linguistic perspective Emotion in Language: Theory - research - application. Consciousness \& Emotion Book Series. 2015. № 10. P. 157-174.

21. SentiStrength. URL: http://sentistrength.wlv.ac.uk (дата звернення: 17.12.2020).

22. Smith Ch. Why Christianity works: An emotions-focused phenomenological account. Sociology of Religion. 2007. № 68 (2). P. 165-178.

23. Stein N.L., Trabasso T., Liwag M.D. The Rashomon phenomenon: The role of framing and future-orientation in memories for emotional events. 
The Development of future oriented processes. Hillsdale, NJ : Lawrence Erlbaum Associates, 1994. P. 409-436.

24. Stone Philip J., Dunphy Dexter C., Smith Marshal S., Ogilvie D.M. The general inquirer: A computer approach to content analysis. Cambridge, MA : The MIT Press, 1966. $651 \mathrm{p}$.

25. Strapparava C., Valitutti A. Wordn et-affect: an affective extension of wordnet. Proceedings of the 4th International Conference on Language Resources and Evaluation. Lisbon, 2004. P. 1083-1086.

26. The Archbishop of Canterbury. Sermons. URL: https://www.archbishopofcanterbury. org/node/464/sermons/sermons/16 (дата звернення: 17.12.2020).

27. Corrigan J. The Oxford handbook on religion and emotion. New York : Oxford University Press, 2008. 522 p.

28. Thelwall M., Buckley K., Paltoglou G., Cai D., Kappas A. Sentiment strength detection in short informal text. Journal of the American Society for Information Science and Technology. 2010. № 61 (12). P. 2544-2558.

29. Turney P.D. Thumbs up or thumbs down? Semantic orientation applied to unsupervised classification of reviews. Proceedings of the 40th annual meeting of the Association for Computational Linguistics (ACL) (July 6-12, 2002). Philadelphia, PA, 2002. P. 417-424.

30. UAM Corpus tool. URL: http://www.corpustool.com (дата звернення: 17.12.2020).

31. Wiebe J., Wilson T., Bruce R., Bell M., Martin M. Learning subjective language. Computational Linguistics. 2004. № $30 \quad$ (3). P. 277-308.

32. Wierzbicka A. Emotion, language, and cultural scripts. Emotion and culture / S. Kitayama \& H.R. Markus (eds.). Washington, DC : American Psychological Association, 1994. P. 133-196.

33. Wierzbicka A. Emotions across languages and cultures: diversity and universals. Cambridge : Cambridge University Press, 1999. 362 p.

Information about the author: Dilai M. P.,

Candidate of Philological Sciences, Associate Professor, Associate Professor at the Department of Applied Linguistics

Lviv Polytechnic National University 12, Stepana Bandery str., Lviv, 79000, Ukraine 